\title{
Decreased cardiac parasympathetic activity in chronic heart failure and its relation to left ventricular function
}

\author{
J Nolan, A D Flapan, S Capewell, T M MacDonald, J M M Neilson, D J Ewing
}

\begin{abstract}
Background-Activation of the sympathetic nervous system has been extensively studied in patients with chronic heart failure, but the parasympathetic nervous system has received relatively little attention. The objective in this study was to investigate cardiac parasympathetic activity in chronic heart failure and to explore its relation to left ventricular function.
\end{abstract}

Methods-Heart rate variability was measured from 24 hour ambulatory electrocardiograms by counting the number of times each $R R$ interval exceeded the preceding $R R$ interval by more than $50 \mathrm{~ms}$ (counts). This method provided a sensitive index of cardiac parasympathetic activity.

Results-Mean (range) of counts were: waking $48(1-275) / h$, sleeping $62(0-360) /$ $h$, and total $1310(31-7278) / 24 \mathrm{~h}$. These were lower than expected, and in 26 $(60 \%)$ of the 43 patients counts fell below the lower $95 \%$ confidence intervals (95\% CI) for $R R$ counts in normal subjects. $A$ significant correlation between total 24 hour RR counts and left ventricular ejection fraction was present $(r=0.49$, p < 0.05).

Conclusions-These results indicate that most patients with chronic heart failure have reduced heart rate variability and therefore reduced cardiac parasympathetic activity. The degree of parasympathetic dysfunction is related to the severity of left ventricular dysfunction. This may be relevant to the high incidence of ventricular arrhythmias and poor prognosis of patients with chronic heart failure.

Departments of Medicine, Medical Physics, and Engineering and Department of Cardiology, Royal Infirmary, Edinburgh J Nolan A D Flapan $S$ Capewell T M MacDonald J M M Neilson D J Ewing

Correspondence to: Dr J Nolan, Department of Medicine, Royal Infirmary, Edinburgh EH3 9YW.

Accepted for publication 30 October 1991 amount of sympathetic activation is linked to symptoms ${ }^{5}$ and haemodynamic indices of impaired left ventricular function. ${ }^{67}$ Although the sympathetic nervous system is activated in chronic heart failure, reflex changes in autonomic activity during stress are impaired. ${ }^{89}$ Increasing sympathetic activation is associated with a progressive rise in afterload leading to a deterioration in myocardial pump function $^{71011}$ and has an inverse relation with survival. $^{12}$ Although abnormal parasympathetic function has also been found in chronic heart failure, this has not been extensively studied..$^{13} 14$

Analysis of variability of heart rate has been developed over the last decade as a useful non-invasive way of measuring activity of the autonomic nervous system. We have developed a method, with 24 hour electrocardiograms, that is a reliable and a specific index of cardiac parasympathetic function, ${ }^{15}$ and is valid even in the presence of frequent ventricular extrasystoles. ${ }^{16}$

Our aims in this study were to determine whether abnormal cardiac parasympathetic activity is present in patients with chronic heart failure and to examine the relation between resting left ventricular function and cardiac parasympathetic function.

\section{Patients and methods}

PATIENTS WITH CHRONIC HEART FAILURE

Sixty ambulatory patients (42 men) with chronic heart failure due to ischaemic heart disease were studied. Their mean age was 61 (range 36-72), and all had moderate limitation of their daily activities, categorised as grade II or III of the New York Heart Association (NYHA) classification. Resting left ventricular function was impaired in all patients. This was assessed by a standard radionuclide technique

Patients were receiving only diuretics to for calculation of ejection fraction. ${ }^{17}$ The mean (range) ejection fraction of patients was $17 \cdot 8$ $(5-35) \%$. All patients were in sinus rhythm. control their chronic heart failure, with a mean (range) frusemide dose of $102(40-160) \mathrm{mg}$. No patient had diabetes or renal failure and their clinical state had been stable for at least three months before the study. No patient had any history or clinical evidence of autonomic neuropathy. Because a recent myocardial infarction may affect cardiac parasympathetic activity, we excluded all patients with a system is deranged in chronic heart failure and contributes to the pathophysiology of the syndrome. ${ }^{3}$ The sympathetic nervous system has been widely studied and its activity is enhanced in chronic heart failure. ${ }^{4}$ The
Unlike most other diseases of the cardioWestern world. ${ }^{2}$ Chronic heart failure is 
documented myocardial infarction during the previous six months.

Tapes from 17 patients were excluded from analysis because of the presence of frequent supraventricular extrasystoles or technical problems with tape quality. There were no significant differences in baseline characteristics between the 43 patients ( 30 men, 13 women) included and the 17 patients (12 men, five women) excluded from further study.

\section{METHODS}

Electrocardiograms were obtained with a miniature tape recorder (Tracker, Reynolds Medical Limited) for 24 hours from all patients during normal ambulant out of hospital activities. Times of going to bed and getting up were noted by the patients.

Tapes were replayed through a Pathfinder arrhythmia analyser (Reynolds Medical Limited) at 120 times the original recording speed. Heart rate variability was then assessed by the count based time domain method we have previously described. ${ }^{15}{ }^{16}$ Briefly, each RR interval was measured and successive beat by beat $R R$ interval differences calculated. Each time an $R R$ interval exceeded the preceding interval by more than 50 milliseconds a count was registered. Counts were accumulated and the results presented as total 24 hour RR counts, mean hourly waking $R R$ counts, mean hourly sleeping $R R$ counts, and mean waking and sleeping heart rates.

Segments of tape in which changes in $R R$ intervals occurred due to the presence of ventricular extrasystoles were excluded from analysis by the Pathfinder arrhythmia analyser, which detected ventricular extrasystoles due to the difference in their morphology and timing. ${ }^{1618}$ As the Pathfinder arrhythmia analyser is unable to detect atrial arrhythmias, the signal was also closely monitored by the operator and tapes in which atrial arrhythmias occurred were discarded. Where less than 24 hours of recording were available for analysis, the results were normalised to the equivalent of 24 hours. Recordings shorter than 18 hours or with less than $40 \%$ of the tape suitable for analysis were rejected.

We have already defined normal age related $95 \%$ confidence intervals $(95 \% \mathrm{CI})$ for counts with the same equipment and technique. ${ }^{19}$ Values obtained from patients with chronic heart failure have been compared with this normal range.

We have discussed the reasons why our technique provides a measure of cardiac parasympathetic activity. ${ }^{1520}$ Abrupt changes in $R R$ interval that occur at the start of muscular exercise, standing up, or lying down, are mediated by the vagus nerve. ${ }^{21-23}$ Variation in RR interval is abolished in animals by cutting the vagus nerve ${ }^{24}$ and in humans by parasympathetic blockade with atropine, ${ }^{20}$ but is unaffected by $\beta$ adrenoreceptor blockade. ${ }^{15}$ Patients with transplanted hearts and diabetic patients with cardiovascular reflex evidence of vagal damage have very little variability in $R R$ interval as measured by our technique. ${ }^{15}$ Also, animal studies suggest that the degree of respiratory sinus arrhythmia is directly related to vagal efferent activity. ${ }^{25-27}$

Our method also correlates well with the high frequency $(>0.15 \mathrm{~Hz}$ ) band of the power spectrum, ${ }^{28}$ which is thought to be mediated by cardiac parasympathetic pathways. ${ }^{2930}$ Our method is probably more specific as a measure of cardiac parasympathetic activity than other commonly used time domain methods. ${ }^{28} \mathrm{RR}$ interval counts that fall below the normal lower 95\% CI therefore represent reduced cardiac parasympathetic activity.

\section{STATISTICAL ANALYSIS}

Because the RR counts are not normally distributed data were log transformed before analysis. A simple linear regression was used to investigate the relation between total 24 hour RR counts and ejection fraction. Counts are expressed as geometric mean (range). Heart rates are expressed as arithmetic mean (SD).

\section{Results}

\section{HEART RATE VARIABILITY}

Group mean (range) counts of $R R$ interval changes were; waking $48(1-275) / \mathrm{h}$ sleeping 62 $(0-360) / \mathrm{h}$, and total $1310(31-7278) / 24 \mathrm{~h}$. Counts were lower than the predicted mean values for normal subjects of the same mean age of 61 years (waking 72, sleeping 122, and total 2512). Figure 1 depicts total 24 hour RR counts plotted against age. Twenty six of the 43 patients fell below the lower $95 \%$ CI for normal subjects. Mean waking (85 (14) beats per min) and sleeping (77 (15) beats per min) were normal.

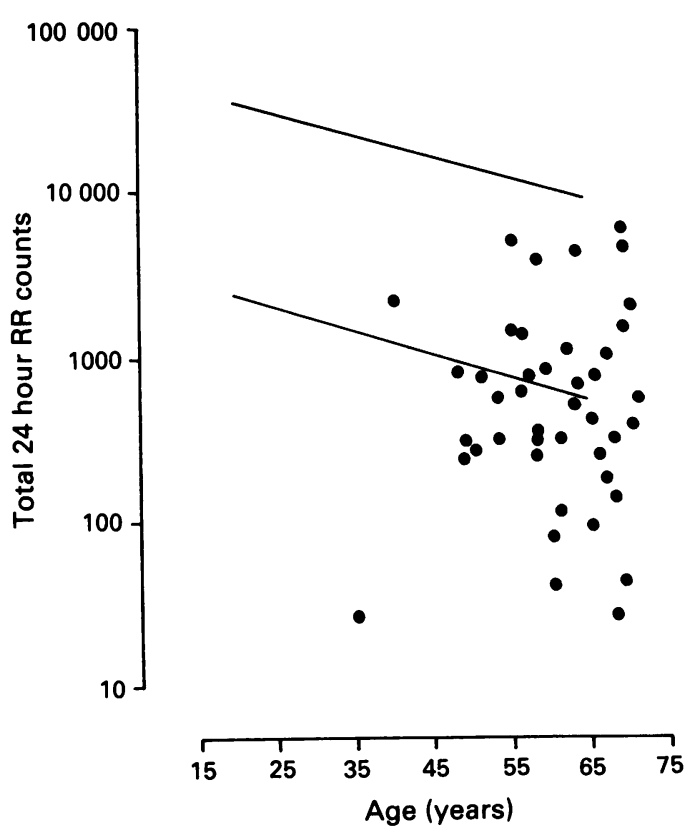

Figure 1 Total 24 hour counts of RR interval changes Figure 1 Total 24 hour counts of RR interval changes plotted against age. Solid lines represent $95 \%$ confide intervals (95\% CI) for counts in normal subjects. had values below the lower $95 \%$ CI. 
Figure 2 Total 24 hour counts of $R R$ interval changes plotted against radionuclide ejection fraction. A significant relation exists, with the lowest counts obtained in those patients with the most severe impairment of left ventricular function.

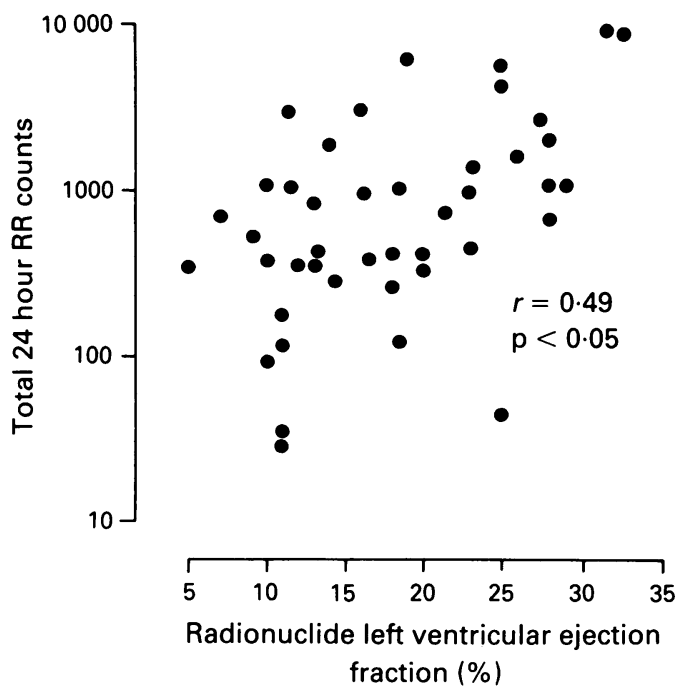

RELATION BETWEEN HEART RATE VARIABILITY AND LEFT VENTRICULAR FUNCTION

Figure 2 shows the relation between total 24 hour RR counts and left ventricular ejection fraction. A significant linear correlation was found with the lowest counts obtained in the patients with the greatest impairment of left ventricular function $(r=0.49, \mathrm{p}<0.05)$.

\section{Discussion}

We have shown in our study that most of our patients with chronic heart failure due to ischaemic heart disease have reduced heart rate variability and by inference, therefore, reduced cardiac parasympathetic activity. Also, we have shown that a significant relation exists between the severity of left ventricular dysfunction and the extent of parasympathetic impairment. These findings have a number of potential implications.

Previous studies have shown that sympathetic activation occurs in chronic heart failure,${ }^{4}$ initially as a compensatory mechanism to maintain adequate central blood pressure. ${ }^{31}$ The role of the parasympathetic nervous system in the pathophysiology and prognosis of chronic heart failure has not been studied in depth. Two previous studies of heart rate variability in chronic heart failure, one using power spectral analysis, ${ }^{32}$ and the other a standard deviation method of analysis, ${ }^{33}$ show a similar pattern of reduced heart rate variability but suffer from certain drawbacks. Standard deviation methods do not clearly differentiate between sympathetic and parasympathetic influences. Power spectral analysis, unlike our method, is rendered unreliable in the presence of ventricular extrasystoles, which occur frequently in patients with chronic heart failure. Our method is specific as a measure of parasympathetic function and clearly shows that impaired cardiac parasympathetic activity occurs throughout the 24 hour period. ${ }^{1516} 192028$

Both resting left ventricular function and the amount of sympathetic activation are linked to prognosis in patients with chronic heart failure. ${ }^{123435}$ Patients with severe impairment of left ventricular function have maximal activation of the sympathetic system. We have shown that a similar relation exists for impaired parasympathetic function.

There are several potential mechanisms to explain the abnormalities we found. The renin angiotensin system is activated in patients with symptomatic chronic heart failure of NYHA grade II and greater treated with diuretics, ${ }^{4637}$ and there is evidence that the amount of this activation is proportional to the clinical severity of the heart failure. ${ }^{38}$ Angiotensin II is known to interact both centrally and peripherally with the autonomic nervous system to enhance sympathetic $c^{39} 40$ and inhibit parasympathetic activity. ${ }^{4142}$ Increasing neuroendocrine activation in patients with chronic heart failure may therefore explain the presence of parasympathetic impairment and its relation to impaired left ventricular function. An alternative or additional mechanism in patients with ischaemic heart disease could be direct injury to intracardiac nerves and receptors, leading to disruption of autonomic reflexes. We have previously shown that parasympathetic impairment occurs early in the course of anterior myocardial infarction. ${ }^{20}$ As chronic heart failure is more likely to occur after anterior than inferior infarction, this lends support to direct damage as a possible mechanism for original parasympathetic impairment in these patients, with increasing neuroendocrine activation contributing to progressive changes in those patients whose left ventricular function declines with time.

Sudden death occurs in almost $50 \%$ of patients with chronic heart failure. ${ }^{243}$ Autonomic imbalance is known to be linked to the production of ventricular arrhythmias that are thought to be the cause of sudden death in most patients with chronic heart failure. ${ }^{44-46}$ The reduction of parasympathetic activity that we have shown to occur in the presence of sympathetic overactivity, may therefore provide suitable conditions for the production of ventricular arrhythmias. We have already investigated the role of the angiotensin converting enzyme inhibitor captopril in regulating parasympathetic activity in chronic heart failure. ${ }^{47}$ Captopril is known to have a beneficial effect on the incidence of ventricular arrhythmias $^{48}$ and sudden death in chronic heart failure. ${ }^{49}$ The increase in parasympathetic activity that we demonstrated along with the reduction in sympathetic activity that is known to occur with captopril treatment, may be relevant to these effects.

We have also studied the effect of class I and class III antiarrhythmic drugs, commonly used in the treatment of ventricular arrhythmias in patients with chronic heart failure ${ }^{16}$ Some class I agents reduce cardiac parasympathetic activity and this may be an important factor in the adverse effect on prognosis that can occur when class I agents are used to treat ventricular arrhythmias in patients with impaired ventricular function. ${ }^{50} \mathrm{By}$ contrast, the class III agent amiodarone does not reduce cardiac parasympathetic activity. This may explain why this.agent does not have an adverse effect ${ }^{51}$ and may improve survival ${ }^{52}$ when used to treat 
ventricular arrhythmias in chronic heart failure.

In conclusion, we have shown that cardiac parasympathetic activity is reduced in most patients with chronic heart failure and that the magnitude of this reduction is correlated with the severity of left ventricular impairment. Reduced heart rate variability is a powerful independent risk factor for sudden death in survivors of myocardial infarction..$^{53}$ Long term follow up studies of patients with chronic heart failure are now needed to find out whether reduced heart rate variability will have a similar predictive value in these patients.

1 Ghali JK, Cooper R, Ford E. Trends in hospitalization rates for heart failure in the United States 1973-1986: evidence for increasing population prevalence. Arch Intern Med 1990;150:769-73.

2 McFate Smith W. Epidemiology of congestive heart failure. Am J Cardiol 1985;55:3A-8.

3 Thomas P, Sheridan DJ. Pathophysiology of autonomic dysregulation in heart failure. In: Bannister R, ed. Autonomic Failure. A textbook of disorders of the autonomic nomic Failure. A textbook of disorders of the autonomic nervous system.

4 Mancia G. Neurohormonal activation in congestive heart failure. Am Heart J 1990;120:1532-7.

5 Thomas AJ, Marks BH. Plasma norepinephrine in congestive cardiac failure. Am J Cardiol 1978;41:233-43.

6 Levine TB, Francis GS, Goldsmith SR, Simon AB, Cohn $\mathrm{JN}$. Activity of the sympathetic nervous system and reninangiotensin system assessed by plasma hormone levels and their relationship to haemodynamic abnormalities in co

7 Francis GS, Goldsmith SR, Cohn JN. Relationship exercise capacity to resting left ventricular performance exercise capacity to resting left ventricular performance and basal plasma norepinephrine levels in patients with

congestive heart failure. Am Heart J 1982;104:725-31.
Levine Trancis GS, Goldsmith SR, Cohn JN. The neurohumeral and haemodynamic response to orthostatic neurohumeral and haemodynamic response to orthostatic tilt in patients

9 Cody RJ, Franklin KW, Kluger J, Laragh JH. Mechanisms governing the postural response and baroreceptor abnormalities in chronic congestive heart failure: effects of acute and long term converting enzyme inhibition. Circulation 1982;66: $135-42$.

10 Dzau VJ, Hollenbery NK, Williams GH. Neurohormonal mechanisms in heart failure: role in pathogenesis, therapy, and drug tolerance. Federation Proceedings 1983;42 3162-9.

11 Francis GW, Goldsmith SR, Levine TB, Olivari MT, Cohn $\mathrm{JN}$. Activity of the sympathetic nervous system and reninangiotensin system assessed by plasma hormone levels and their relation to haemodynamic abnormalities in congestheir relation to haemodynamic abnormalities in

12 Cohn JN, Levine TB, Olivari MT, Carberg V, Lura D, Francis GS, Simon AB, Rector T. Plasma norepinephrine as a guide to prognosis in patients with chronic congestive as a guide to prognosis in patients with chronic
heart failure. $N$ Engl $\mathrm{J} \mathrm{Med} \mathrm{1984;311:119-23.}$

13 Eckberg DL, Drabinsky M, Braunwald E. Defective cardiac parasympathetic control in patients with heart disease. N Engl J Med 1971;285:877-83.

14 Goldstein RE, Beiser GD, Stampfer M, Epstein SE. Impairment of autonomically mediated heart rate control in patients with cardiac dysfunction. Circ Res 1975;36: 571-8.

15 Ewing DJ, Neilson JMN, Travis P. New method for assessing cardiac parasympathetic activity using 24 hour electrocardiograms. Br Heart J 1984;52:396-402.

16 Zuanetti G, Latini R, Neilson JMM, Schwartz PJ, Ewing DJ. Heart rate variability in patients with cardiac arrhythmias: effect of antiarrhythmic drugs. J Am Coll Cardiol mias: effect of a

17 Wathen CG, Muir AL, Hannan WJ. Radionuclide studies of left ventricular function in normal subjects. Nucl Med left ventricular function in

18 Neilson JMN. Computer detection of ventricular ectopic beats: On line and off. In: Computers in cardiology. Lo Alamitos: IEEE Computer Society Press, 1975:33-5.

19 Ewing DJ, Neilson JMM, Shapiro CM, Steward JA, Reid W. 24 hour heart rate variability: effects of posture, sleep and time of day in normal subjects and comparison with bedside autonomic function tests in diabetic patients. Br Heart J 1991;65:239-44.

20 McAreavey D, Neilson JMM, Ewing DJ, Russell DC. Cardiac parasympathetic activity during the early hours of acute myocardial infarction. Br Heart $J$ 1989;62:165-70.

21 Fagraeus L, Linnarsson D. Autonomic origin of heart rate fluctuations at the ons

22 Ewing DJ, Hume L, Campbell IW, Murray A, Neilson JMM, Clarke BF. Autonomic mechanisms in the initial heart rate response to standing. J Appl Physiol heart rate respon

23 Bellavere F, Ewing DJ. Autonomic control of the immediate heart rate response to lying down. Clin Sci 1982;62:57-64.

24 Samaan A. The antagonistic cardiac nerves and heart rate.
J Physiol 1935;83:332-40.

25 Katona PG, Tih F. Respiratory sinus arrhythmias: noninvasive measure of parasympathetic cardiac control. J Appl Physiol 1975;39:801-5.

26 Eckberg DL. Human sinus arrhythmias as an index of vagal cardiac outflow. J Appl Physiol 1983;54:961-6.

27 Eckberg DL. Parasympathetic cardiovascular control in human disease: a review of methods and results. $A m$ Physiol 1980;239:H581-93.

28 Myers GA, Martin GJ, Magid NM, Barnett PS, Schaad JW, Weis JS, Lesch M, Singer DH. Power spectral analysis of heart rate variability in sudden cardiac death: comparison heart rate variability in sudden cardiac death: comparison

29 Askelrod S, Gordon D, Ubel FA, Shannon DC, Barger AC Cohen RJ. Power spectrum analysis of heart rate fluctuation: a quantitative probe of beat-to-beat cardiovascula control. Science 1981;213:220-3.

30 Pomeranz B, Macauley RJB, Caudill MA, Kutz I, Adam D, Gordon D, et al. Assessment of autonomic function in humans by heart rate spectral analysis. Am J Physio 1985;248: H151-3.

31 Zelis R, Mason DT. Compensatory mechanisms in congestive heart failure - the role of the peripheral resistance vessels. N Engl J Med 1970;282:962-4.

32 Saul JP, Yutaka A, Berger RD, Lilly LS, Collucci WS Cohen RJ. Assessment of autonomic regulation in chronic congestive heart failure by heart rate spectral analysis. $\mathrm{Am}$ J Cardiol 1988;61:1292-9.

33 Casolo G, Balli E, Taddei T, Amuhasi J, Gori C. Decreased spontaneous heart rate variability in congestive heart failure. Am J Cardiol 1989;64:1162-7.

34 Unverferth DV, Magorien DR, Moeschberger ML, Bake PB, Fetters JK, Leier CV. Factors influencing the one yea mortality of dilated cardiomyopathy. Am J Cardiol 1984;54:147-52.

35 Schwarz F, Mall G, Zebe H, Schmitzer E, Martley J, Scheurien H, Kubler W. Determinants of survival in patients with congestive cardiomyopathy: quantitative morphological findings and left ventricular haemodynamics. Circulation 1984;70:923-8.

36 Genest J, Granger P, De Champlain J, Boucher R. Endocrine factors in congestive heart failure. Am J Cardiol 1968;22:35-42.

37 Laragh JH. Endocrine mechanisms in congestive heart failure. Renin, aldosterone and atrial naturetic hormone. failure. Renin, aldosterone and
Drugs 1986;32(suppl 5):1-12.

38 Dzau VJ, Colucci WS, Hollenbery NK, Williams GH. Relation of the renin-angiotensin aldosterone system to clinical state in congestive heart failure. Circulation 1981;63:645-51.

39 De Jonge A, Knape JTA, Van Meel JCA, et al. Effect of captopril on the sympathetic neurotransmission in pithed normotensive rats. Eur J Pharmacol 1983;88:231-5.

40 Zimmerman BG. Adrenergic facilitation by angiotensin: does it serve a physiological purpose. Clin Sci $1981 ; 60: 343-4$

41 Potter EK. Angiotensin inhibits the action of the vagus nerve at the heart. Br J Pharmacol 1982;75:9-11.

42 Lumbers ER, McCluskey DI, Potter EK. Inhibition by angiotensin II of baroreceptor evoked activity in cardiac angiotensin II of baroreceptor evoked activity

43 Packer M. Sudden unexpected death in patients with congestive heart failure: a second frontier. Circulation congestive heart

44 Schwartz PJ. Sympathetic imbalance and cardiac arrhythmias. In: Randall WC (ed). Nervous Control of Cardiovascular Function. Oxford: Oxford University Press 1984:225-52.

45 Verrier RL, Lown B. Sympathetic parasympathetic interactions and ventricular electrical stability. In: Schwartz PJ Brown AM, Malliani A, Zanchetti A, eds. Neural Mechanisms in Cardiac Arrhythmias. New York: Raven Press, 1977:75-86.

46 McAreavey D, Neilson JMN, Russell DC. Evidence for reduced vagal tone preceding ventricular fibrillation in man. Eur J Clin Invest 1986;16:A5

47 Flapan AD, Nolan J, Neilson JMM, Ewing DJ. Captopril therapy increases parasympathetic activity in patients with congestive cardiac failure. Circulation 1990;82(suppl with congest 382 .

48 Cleland JGF, Dargie HJ, Hodsman GP, Ball SG, Robertson JIS, Morton JJ, et al. Captopril in heart failure-a double JIS, Morton JJ, et al. Captopril in heart failure-

49 Newman TJ, Maskin CS, Dennick LG, Meyer JH, Hallows BG, Cooper WH. Effects of captopril on survival in patients with heart failure. Am J Med 1988;84:140-44.

50 The Cardiac Arrhythmia Suppression Trial (CAST) Investigators. Preliminary report. Effect of encainide and flecainide on mortality in a randomised trial of arrhythmia suppression after myocardial infarction. New Engl J Med 1989;321:406-12.

51 Stewart RA, McKenna WJ, Poloniecki JD, Michelson JK, Das SK, Morady F, et al. Prospective randomised double blind placebo controlled trial of low dose amiodarone in patients with severe heart failure and frequent ventricula extra systoles. Br Heart $J$ 1989;61(S):459-60.

52 Cleland JFG, Dargie HJ, Findlay IN, Wilson JT. Clinica haemodynamic and anti arrhythmic effects of long term treatment with amiodarone of patients in heart failure. $B$ Heart $J$ 1987;57:436-45.

53 Kleiger RE, Miller JP, Bigger JT, Moss AJ. Multicentre post infection research group. Decreased heart rate
variability and its association with increased mortality after acute myocardial infarction. Am J Cardiol 1987;59:256-62. 